ARTIGOS

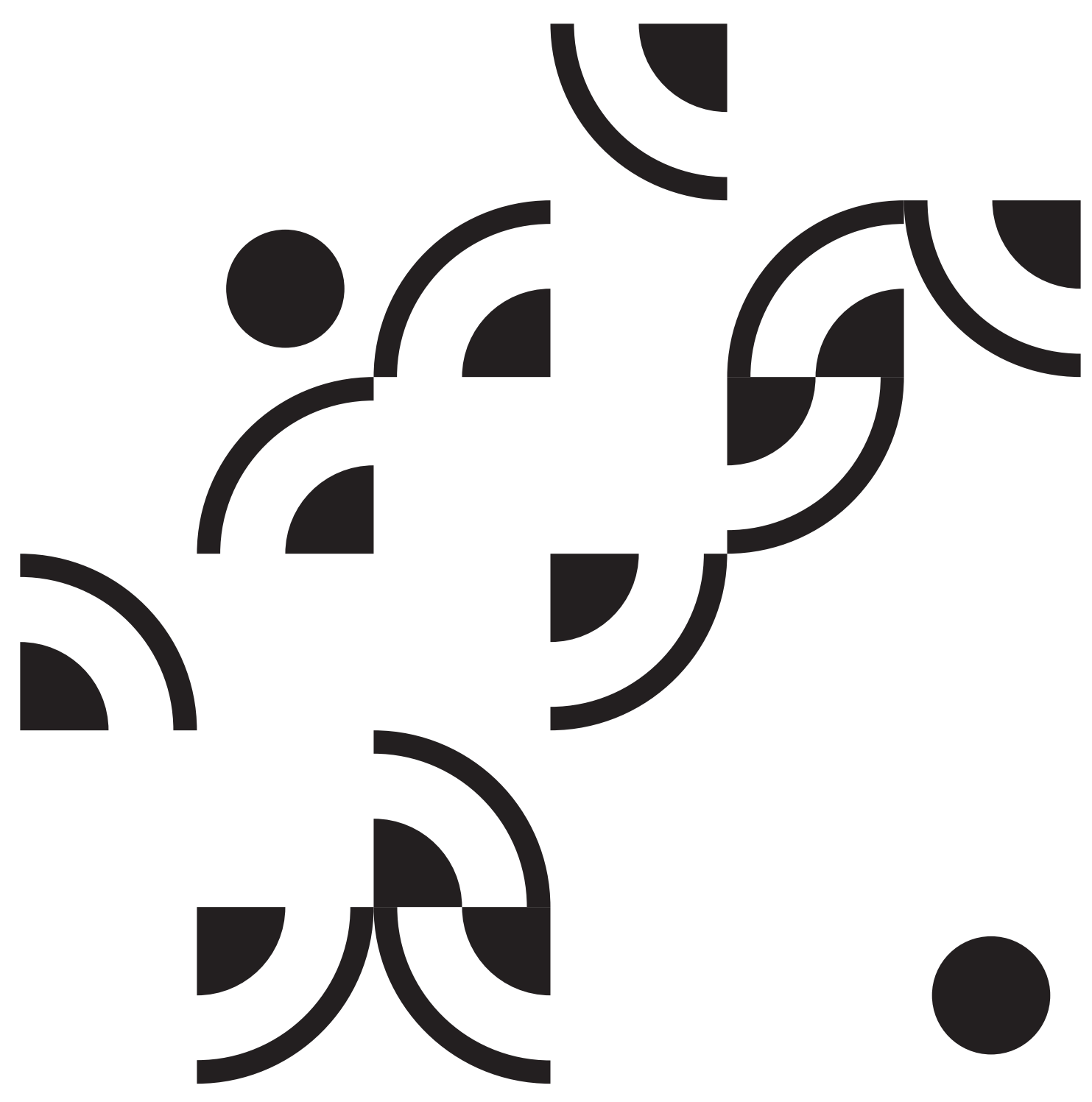




\title{
Educação, infância e leitura: contribuições da teoria dos processos civilizadores de Norbert Elias
}

\author{
Juliana Bernardes Tozzi*
}

\section{Resumo}

0 artigo se propõe a destacar algumas contribuições da teoria dos processos civilizadores do sociólogo alemão Norbert Elias para estudos na área da educação e da cultura que abordam a leitura, seus objetos e práticas, e, enfim, para os que versam sobre a produção e o consumo dos livros destinados à forma* Professora do Ensino Fundamental I do Colégio Rio Branco (Campinas), Brasil. juliana.bernardes@ bol.com.br ção das novas gerações. Num primeiro momento do texto, introduz-se a obra em que o autor desenvolve a teoria sobre os processos civilizadores, apresentando sua organização e premissas gerais. A seguir, discute-se como a compreensão sobre o processo de constituição das sociedades modernas ocidentais - seguindo as proposições de Elias - oportuniza fecundas contribuições para uma abordagem histórica e sociológica dos objetos de consumo cultural voltados à infância, especialmente os livros: objetos por excelência da "civilidade".

\section{Palavras-chave}

leitura e civilidade; teoria dos processos civilizadores; leitura e infância; livros infantis. 


\title{
Education, childhood and reading: contributions of the theory of civilizing processes by Norbert Elias
}

\begin{abstract}
The article intends to highlight some contributions of the theory of the German sociologist Norbert Elias for studies in the area of education and culture which deal with reading, its objects and practices, and, especially, for studies regarding the production and consumption of books destined for new generations' education. Firstly, the text introduces the work in which the author develops the theory on civilizing processes, with its organization and general assumptions. Next, it discusses how the understanding of the process for the formation of modern western societies - according to Norbert Elias' ideas - presents productive contributions to a historical and sociological approach of the objects of cultural consumption destined to childhood, specially the books: objects by excellence of civility.
\end{abstract}

Key words reading and civility; theory of civilizing processes; reading and childhood; children's books. 


\section{A obra 0 processo civilizador}

Publicada na Alemanha, em 1939, com o título Über den Prozess der Zivilisation, a obra escrita pelo sociólogo alemão Norbert Elias (1897-1990) teve sua primeira edição, limitada e com pequena difusão.

A comunidade científica voltou sua atenção ao trabalho somente em 1969, quando da nova edição alemã. Vieram então as traduções francesa (1973/75), inglesa (1978) e italiana (1982/83). No Brasil (1990 e 1993), sua publicação seguiu o formato da tradução inglesa, com subtítulos distintos: o volume I, O processo civilizador: uma história dos costumes e o volume II, O processo civilizador: formação do estado e civilização. ${ }^{1}$

Considerada a principal obra de sua carreira, Norbert Elias apresenta, em O processo civilizador, o programa de uma vasta pesquisa sociológica realizada na Biblioteca do Museu Britânico desde 1935, período em que abandonou a tentativa de alcançar um posto universitário na sociedade francesa para a qual imigrara por ocasião do clima político desfavorável em seu país. Esse programa foi permeado pelas indagações que já o envolviam desde seu primeiro trabalho sociológico, "A Sociedade de Corte", desenvolvido na Universidade de Frankfurt, quando, então, foi aluno assistente de Karl Mannheim, e concluído no início dos anos 1930.

De família judaica e educado em um meio de práticas “cultivadas”, Elias confirmou, nesse empreendimento, a busca pelo desenvolvimento de uma teoria para 0 processo de constituição das sociedades ocidentais modernas. Mobilizaram-no, por certo, as paixões pela cultura, pelos costumes e pela história (Leão, 2007). Pela França, também, conforme nunca escondeu. Trata-se de uma produção que reflete, também, a experiência de um intelectual que viveu de perto todo o processo da tomada do poder pelo nacional-socialismo na Alemanha. Em Norbert Elias por ele mesmo, revisando o conjunto de sua obra, Elias indica uma contribuição para a elucidação do velho problema das mentalidades nacionais; e também, uma experiência de descoberta de que só se pode entender a estrutura das sociedades comparando-as sistematicamente: "fiz isso desde essa época. Não me contento em constatar que a mentalidade nacional dos alemães é diferente da dos franceses, mas explico por que" (Elias, 2001, p. 66).

Buscando evidências, que chama de empíricas, para a hipótese de que o processo de civilização das maneiras segue uma direção - não planejada -

1. Parte dessas considerações iniciais foi tomada da nota de apresentação da edição portuguesa do livro $A$ condição humana (Elias, 1991). Segundo Janine Ribeiro, a intervenção editorial da tradução inglesa foi refutada pelo autor (ver seu prefácio no primeiro volume da edição brasileira). 
que acompanha as novas formas de organização social, o autor observa como ela aponta para uma maior contenção dos impulsos, para a privatização e para a individualização das práticas.

Elias marcou um proceder metodológico e analítico atento à renovação e à problematização das fontes, inscrito nos princípios de uma sociologia dos processos - ou, de uma história de longa duração. Como a obra atesta, o autor idealizou todo este programa de pesquisa a partir de um específico arsenal de materiais que lhe instigou curiosidade e teorização: os manuais de conduta e tratados de etiqueta do século XVII. Uma original suposição teórica, nascida de observações dispersas a respeito de mudanças de longo prazo nas emoções e nos padrões comportamentais dos sujeitos, motivou-o a buscar explicações científicas para o desenvolvimento das sociedades ocidentais capitalistas.

0 reconhecimento tardio de uma tese que sinalizava a carência de novas formas de se falar e se pensar a sociedade, contrasta-se com o potencial heurístico que conferiu ao desenvolvimento das ciências humanas e sociais, relevância atestada pela interlocução que continua a estabelecer com obras inspiradas em intelectuais de renome como Phillippe Ariès, Pierre Bourdieu e Roger Chartier, entre outros.

As ideias de Elias oferecem mote a várias chaves de abordagem e de inspiração para o estudioso das questões políticas e culturais que acompanham o desenvolvimento das sociedades do Ocidente. Neste texto será percorrida uma aproximação àquelas que se mostram particularmente oportunas para a abordagem de trabalhos relacionados à educação da infância e, enfim, à produção cultural destinada às novas gerações. ${ }^{2}$

\section{A teoria dos processos civilizadores ou uma teoria da educação}

A teoria dos processos civilizadores é desenvolvida em uma obra que, nos

2. As reflexões organizadas pelo presente trabalho puderam ser sistematizadas durante o curso de Seminário Avançado "Norbert Elias, Sociologia e Educação", oferecido, no $2^{\circ}$ semestre de 2011, na pós-graduação da Faculdade de Educação da Unicamp sob docência da Profa. Dra. Aparecida Neri de Souza. 0 conteúdo, do que aqui se apresenta, inspirou o desenvolvimento da dissertação de mestrado intitulada "Livro infantil no Brasil (2007-2008): marcas em circulação, catálogos de divulgação e infâncias anunciadas", concluída em 2011 no grupo Alfabetização, Leitura e Escrita (ALLE), na mesma faculdade, com orientação da Profa. Dra. Lilian Lopes Martin da Silva e financiamento do Cnpq. dizeres anunciados pelo próprio Elias, abrange "os tipos de comportamento considerados típicos do homem civilizado ocidental” (Elias, 1994b, p. 13). Grandes questões que acompanham a história do conhecimento humano, no Ocidente, quais sejam, “o que é o homem?”, “o que é a cultura?”, “como nos tornamos no que somos?", "por que nos comportamos de certa forma?" orientaram o autor no trabalho. 
Elias, que está em busca da sociogênese do processo de civilização das sociedades ocidentais, das formas pelas quais se desenvolveu uma rede de transformação lenta e global na vida dos seus grupos humanos, introduz seu estudo por meio da análise de dois processos civilizadores exemplares no Ocidente; desse modo, volta-se à busca das ideias historicamente inscritas no processo civilizador moderno da Alemanha e da França.

Assim procedendo, o autor aponta as alterações de sentido das palavras que acompanham as novas formas de autoimaginação dos grupos humanos (re)integrados, mostrando como elas só podem ser entendidas e significadas mediante os pilares de uma sociologia das relações de poder. Em outras palavras, a análise que empreende em busca de uma gênese dos processos civilizadores indica como as palavras - no caso, Kultur e Civilisation, articuladas, respectivamente, ao projeto civilizador alemão e francês - formaram-se com base na história concreta dos homens, ou seja, nas tensas e dinâmicas relações que travaram entre si e que lhes demandaram lutas e (re) posicionamentos. As palavras e os conceitos, diz, "crescem e mudam com o grupo do qual são expressão. Situação e história do grupo refletem-se nelas" (Elias,1994b, p. 26).

Nesse sentido, Elias aponta que a rigidez peculiar da estrutura social da sociedade alemã conferiu-lhe um desenvolvimento histórico, social e político profundamente caracterizado por tendências para distinções e exclusões, com maior duração, o que determinou um sentimento nacional que sofreu com tais oposições e fragmentações. ${ }^{3}$ Quanto ao projeto civilizador francês, Elias explicita como a intelligentsia burguesa francesa sentiu-se atraída mais cedo que a alemã para a sociedade aristocrática cortesã. Mas não por acaso e, sim, aproveitando-se das marcas de um desenvolvimento histórico diferenciado que confluiu tanto para zonas mais flexíveis em termos de mobilidade social como, por isso mesmo, para o que se poderia identificar como um posicionamento estratégico nas tensas redes de convivência com a aristocracia da corte, posicionamento esse que se tornou decisivo para a elaboração de noções de civilidade nessa nação. ${ }^{4}$

3. A antítese que 0 autor evidencia, por meio das fontes de pesquisa das quais lança mão, entre a Civilisation e a Kultur, neste país, mostra-se, portanto, como uma antítese historicamente travada entre a aristocracia de corte e a burguesia nascente, e que, bem mais tarde, sob nova configuração histórica, deslocou-se, marcando a distinção nacional elaborada pelos alemães em relação às outras nações europeias (ou seja, pela Kultur).

4. Deste modo, o sentimento de superioridade de uma tradicional classe francesa aristocrática (evidenciado em termos como politesse e civilitê) teria se seguido, na história, pelo desenvolvimento de uma aspiração (tipicamente burguesa) à civilisation, correspondente a um padrão de costumes que, diferentemente do caso alemão, veio a absorver muito do arsenal de valores e práticas da própria corte. 
Processos civilizadores, nessa perspectiva, não se configuram como projetos advindos de ideias a priori, mas constituem direções tomadas pelo desenvolvimento das sociedades ocidentais. Eles trazem inúmeras exigências imediatas aos que chegam a um mundo cujas formas foram definidas por longos períodos de história. 0 autor não se preocupa em analisar se essas transformações foram para melhor ou para pior; realça, apenas, que foram não planejadas. ${ }^{5}$ Deste modo, questiona que tipo de mudanças foram essas. Em seguida, propõe-se à tarefa de entender como poderiam ser explicadas. Grosso modo, encontramos assim o conteúdo geral dos dois volumes da obra.

0 autor descreve detidamente como a ideia de civilité - ele está partindo das lentas transformações que ocorrem no ocidente europeu medieval - ganha força numa época em que a sociedade cavaleirosa e a unidade da Igreja se esboroavam, e em que uma formação social específica, que aglutinava as mais variadas origens, foi ali se constituindo. Nela, o grande centro político, econômico e cultural apontou para a corte feudal, que passou a se autoimaginar por meio daquele ideário (a "civilité"). ${ }^{6}$ Mas esse ideal, como tudo em Elias, não localiza aí um ponto zero de origem: seja na Antiguidade com a questão dos "comportamentos socialmente desejáveis"; seja na Idade Média, com a "courtoisie", que expressava um comportamento que distinguia a alta classe secular um ideal gestado nas cortes dos senhores feudais. 0 autor mostra um processo social

5. De fato, porém, foram inevitáveis as críticas para seu trabalho que reconheceram nele um caráter eurocêntrico (Goody, 2009); também, evolucionista. Elas renderam várias respostas do autor - algumas das quais encontradas no próprio corpo revisado da obra 0 processo civilizador. Como Elias insiste, seu olhar para o desenvolvimento das sociedades que, no Ocidente, passaram a figurar-se como Estados-Nações, foi tanto limitado pela observação de sociedades específicas, quanto, defende, desapegado de juízos de valores. Apesar de especialmente polêmico quanto a esse último ponto e, também, apesar de assumir o desenvolvimento de ideias e proposições que não vinham sendo discutidas a partir ou apenas com ele, é justo reconhecer as contribuições que 0 autor apresenta em seu esforço teórico para a compreensão da constituição das formas e das maneiras das sociedades capitalistas ocidentais.

6. Para Elias, este movimento que confere centralidade à corte não se explica por um fator fundamental de determinação, tampouco previsível totalmente, mas pela história dos homens em suas tensas relações em busca de sobrevivência e segurança. Como melhor se discute no segundo volume de 0 processo civilizador, aqui estaria a gênese da constituição dos modernos estados nacionais. que vai reagrupando, em níveis cada vez maiores de independência, os grupos, o que lhes exige adaptação e (re)invenção de padrões de convivência, reconhecimento e distinção - padrões que não poderíamos precisar em termos de marco de origem.

Ao recuperar as cenas de vida de um cavaleiro da Idade Média - encontradas no Livro de Imagens da Idade Média, do século XV - ou ao se deter na análise do conteúdo de um dos best-sellers do século XVI - o manual Da civilidade pueril, de Erasmo de Roterdã -, Elias mostra como as sensibilidades respondem a configurações específicas, no caso, como o conceito de civilité se refere simultaneamente à menor possibilidade de vazão espontânea dos impulsos e sentimentos, à "tendência cada vez maior das pessoas a se observarem e aos demais" 
(Elias,1994b, p. 91), a um novo estado que foi se desenvolvendo junto e gradualmente articulado às mudanças pelas quais passava a sociedade cortesã. Comportamentos, portanto, que prosseguirão em desenvolvimento responsivo às configurações da história, culminando no século XVIII na ideia de civilisation. Eles jamais "aparecem do nada", mas são constitutivos de mudanças estruturais integradas, que vão evoluindo com elas, nelas, respondendo a elas. A noção de sociologia configuracional eliasiana vê-se assim estabelecida: mudanças estruturais das sociedades imbricam-se a mudanças de estrutura de personalidades. Aquele sentido geral do processo civilizador comprovado pelo autor - o aprimoramento de conduta, o maior nível de embaraço e a privatização das práticas - mostra, ao mesmo tempo, que as ideias de cortesia, civilidade e civilização "assinalam três estágios de desenvolvimento social. Indicam qual sociedade fala e é interpelada" (Elias, 1994b, p. 112-113).

Os exemplos de que Elias lança mão são abundantes, ali o leitor pode observar como maneiras rotineiras mais ou menos "comuns" de nos comportarmos, hoje, com objetos corriqueiros do cotidiano (um garfo, uma faca) não foram constituídas nem por uma razão "higiênica”, nem tampouco dadas por termos definitivos, evidentes. $\mathrm{Na}$ verdade, aquilo que veio a se tornar a “educação das boas maneiras" revela um desenvolvimento atrelado em seus primórdios, simplesmente, ao que poderíamos identificar como lembranças indesejáveis da não contenção dos impulsos, a um sentimento de desagrado e insegurança. No devir histórico, gradualmente, práticas e ameaças efetivadas para a correção de hábitos possivelmente geradores de desagrado/ansiedade viraram rituais: cristalizaram-se, e o aprendizado daquilo que foi significado/constituído numa história de muito longa duração passou a ocorrer em um curto período de tempo: a infância. Tais práticas e ameaças se tornaram o material da civilização, quer dizer, da civilização dos costumes, da educação.

0 autor sugere que essa direção, portanto, caminhou em função articulada (1) ao menor distanciamento das convivências plurais que passaram a exigir dos grupos novas formas de comportamento, (2) à maior divisão das funções sociais e da decorrente interdependência (e individualização) entre os grupos humanos que implicou aos homens a construção de modos de reconhecimento e (3) a uma sociedade que começou a limitar cada vez mais os perigos que a ameaçavam e, assim, a exercer um domínio maior sobre o mundo e sobre si mesma. Sempre em busca da sobrevivência. ${ }^{7}$

7. Esse seria, para Elias, o fim último da vida social, "arena” cuja compreensão é aprofundada pelo modelo dos jogos, apresentado no terceiro capítulo de Introdução à Sociologia (Elias, 2008). 
Vemos que pensar as questões da educação e da cultura, com o autor, é um convite para compreendermos o processo civilizador como aquele que nos confere o passaporte para o convívio entre os homens, mediante a interiorização de modelos de conduta, o que pode suscitar diretamente a evocação de autores como Émile Durkheim ou Sigmund Freud, evidentemente interlocutores de sua obra. Mas Elias está falando de um processo, cujo eixo de análise fundamental é a configuração social e, nessa perspectiva, as redes de interdependência implicam o entendimento de que não há indivíduo educado sem uma sociedade de sua educação; e, da mesma forma como essa constitui os sujeitos, eles a constituem, num movimento em que o fluxo é a lei. Portanto, nada aparece como evidente, nem completamente definitivo.

\section{Artefatos da cultura como fontes para o estudo de uma história sociológica dos grupos humanos}

Elias interpela e deixa falar a sociedade, por meio de seus materiais literários, de seus manuais de civilidade, além de outros recursos - são as evidenciações empíricas, tomadas pelo autor em sua investigação. Ele a analisa a partir de um renovado estabelecimento e uso das fontes. Não é por acaso que Janine Ribeiro, prefaciando a obra, chama a atenção para este investimento original, didático e profícuo em relação ao "pormenor, à minúcia, ao irrelevante" da história.

Elias estabelece fontes que podemos apontar como alternativas. Opera com elas em função de uma hipótese teórica que busca confirmar e sistematizar: a da direção tomada pelos processos civilizadores. Por meio delas, dos princípios da sociologia das relações de poder e dos processos de longa duração, apresenta quadros aproximativos para explicar os funcionamentos das configurações épicas que vai sobrevoando.

Eis as cenas. Como posicionar-se à mesa? No quarto? Como manusear uma faca? E um garfo? Assoar-se: como proceder ao ter essa necessidade?

Assistimos a homens e mulheres que, diante dessas questões, não parecem preocupados com futilidades: antes, estão profundamente envolvidos com seu estar no mundo. São agentes efetivos do desenvolvimento da condição humana moderna incorporada por nós, a qual desperta certa estranheza/repugnância ao acompanhamos as prescrições que foram, pouco a pouco, delineando-a.

De fato, a todo o momento, o autor mostra que as respostas encontradas nos tratados de civilidade sinalizam materializações de específicas relações e comporta- 
mentos da vida social e mental de homens e mulheres, de um nível de sensibilidade, constrangimento e funcionamento psicológico sempre em contínuo desenvolvimento (do século XII ao XVIII). A linha de evolução, que tais respostas mostram, aparece mais ou menos comum em diferentes situações e tradições do Ocidente (na Alemanha, na França, na Inglaterra, na Itália). São comportamentos que confirmam tanto a maleabilidade psíquica dos seres humanos diante das novas configurações como o concomitante condicionamento a práticas exigidas para viver em (certa) sociedade. Elias (1994b,p.94) ensina que:

Não é tarefa das mais fáceis tornar esse movimento bem visível, sobretudo porque ele ocorre com grande lentidão [...] e porque nele acontecem também múltiplas flutuações, seguindo curvas mais curtas ou mais longas [...]. Temos que tentar enfocar o próprio movimento, ou pelo menos um grande segmento dele, como um todo, como se acelerado. Imagens devem ser postas juntas em uma série, a fim de proporcionar uma visão geral, de um aspecto particular, do processo que se desenrola: a transformação gradual de comportamentos e emoções, o patamar, que se alarga, da aversão.

As fartas descrições disponibilizadas são situadas como exemplos de como se formou o que o autor nomeia por nosso "ritual diário" de viver, advindo, portanto, de um processo do qual os homens continuam participando, em que novos imperativos são acrescidos, relaxados outros e pelo qual se foi definindo (e continuará sendo) a riqueza de variações nacionais e sociais, paralela ao confronto progressivo de novos grupos humanos a um mesmo processo da civilização (que se inscreve, pois, no desenvolvimento das formas capitalistas de produção das sociedades ocidentais). Justamente e não por acaso, a teoria de Elias acentua que o processo civilizador deve ser estudado em toda sua polifonia, de muitas camadas, e não como um processo linear entre os vários grupos ou povos, mas como uma dinâmica concorrencial que vai, historicamente, implicando diferentes movimentos de apropriação, reinvenção e reconfiguração.

O esforço de descrições do autor potencializou sua tese a respeito da conexão entre estruturas sociais e estruturas de personalidade. Permitiu-lhe reconhecer que o processo civilizador é o processo pelo qual tornamo-nos homens e mulheres de específicas sociedades, mediante as práticas difusas (e, também, institucionais) de 
educação. Desde que nascemos tais práticas nos fundem a um ideal de ser, perceber, agir, sentir e estar no mundo ao qual respondemos, pois a figura humana, em Elias, da mesma forma que a sociedade, é mudança, é processo, é um tornar-se constante, é uma relação. ${ }^{8}$ Portanto, a discordância de Elias sobre a divisão em dois tomos de sua obra, com subtítulos diferentes - conforme a edição inglesa, o primeiro enfatizando a mudança dos costumes e o segundo a formação dos estados nacionais - é evidentemente justificável, considerando-se a matriz teórica fundamental para o desenvolvimento de toda sua produção, exposta nos termos de que "a questão porque o comportamento e as emoções dos homens mudam é, na realidade, a mesma pergunta por que mudam suas formas de vida" (Elias,1994b, p. 202).

Formas que mudam lentamente e que conferem os modelos de conduta que se apresentam aos sujeitos assim que chegam ao mundo. Mas, se ninguém chega educado ao mundo e nem é educado das mesmas formas, tampouco conclui um processo que tem ponto de chegada definido: a civilização continua...

Continua por meio de seus objetos e práticas, entre os quais, podemos agora meIhor destacar: a leitura.

\section{A civilidade e a infância mediadas pela cultura: um olhar para os livros destinados às novas gerações}

Elias considera a moderna distância estabelecida entre crianças e adultos como o produto continuum de um desenvolvimento de longa duração, o qual levou os adultos a, progressivamente, afastarem-se de um estado de não educação, próprio da condição do infante. ${ }^{9}$ Assim, da "infância" é eliminado qualquer sinal de evidência atrelado à ideia de um funcionamento psicológico "comum”, de um intervalo cronológico "natural”.

A importante contribuição desse raciocínio para estudos relacionados à área dos produtos para o consumo da infância é que aquilo que aí se caracteriza como "infantil" ou "próprio da infância" passa a ser reconhecido como algo que não abraça todas as culturas e, tampouco, se relaciona a um funcionamento psíquico que envol-

8. Esta discussão pode ser aprofundada pela leitura de Elias, 1994a.

9. De forma semelhante a Ariès (2006), que observou as raízes de um sentimento moderno de infância, no Ocidente, na sua relação com a história da constituição de um tempo-espaço que foi se tornando repositório das práticas abandonadas pelos adultos, quer dizer, no lento processo de modernização de seus modos de produção e de vida. va todas as crianças de uma mesma cultura (Gélis, 2009). Concomitantemente, a infância não se mostra explicada por uma condição que existiu desde sempre ou que existirá nos mesmos termos para todos os grupos humanos participantes de uma mesma sociedade e época (Elias, 1993, p. 70). 
Vemos que a história da consciência da especificidade da infância e, consequentemente, de materiais apropriados a ela - entre esses, livros - pode ser lida, assim, circunscrita ao desenvolvimento do processo civilizador. E, a propósito, acentuará Elias que "o aumento da demanda de livros numa sociedade constitui bom sinal de um avanço pronunciado no processo civilizador, porque sempre são consideráveis a transformação e regulação de paixões necessárias tanto para escrevê-los como para lê-los" (Elias, 1993, p. 229).

Não por acaso, é interessante observar que os primórdios mais distantes das leituras infantis nos apontam para aqueles modelos de livros destinados à educação ou à correção moral dos comportamentos dos sujeitos de sociedades em processo de nacionalização. A história desses artefatos articula-se, pois, à constituição de um mundo bem mais amplo de prescrições sobre formas de fazer e de estar no mundo organizadoras e distintivas - que foram sendo encontradas e aspiradas pelas classes burguesas em resposta a novas relações sociais. Portanto, participando desse universo, localizamos, a partir do século XVIII, esses objetos privilegiados de/da "civilização", preocupados com a formação moral das crianças - livros infantis.

Atuantes nos processos de aprendizado da vida em grupo e na formação das disposições comportamentais, esses livros aparecem como objetos que formam porque ensinam formas de ser e estar no mundo: que apresentam às crianças uma ordem para os espaços de sua existência e expressão, que funcionam reorganizando simbolicamente os lugares ocupados por públicos que detêm sua propriedade ou apropriação conformada a certa prática.

Livros, portanto, que materializam projetos de civilidade, que educam os corpos e as rotinas, que regulam paixões, que conformam aspirações e sensibilidades.

A tríade que se pode estabelecer pela leitura de 0 processo civilizador entre "infância - civilidade - livros" instiga o olhar para os livros infantis de outras épocas (e a nossa) como ocasião privilegiada para adentrarmos, com eles, à configuração de determinada sociedade, neles inscrita por meio de distâncias e cuidados, temas e formatos, aspirações e sensibilidades e, por fim, concorrências de valores.

Dito de outra forma, ao darem pistas sobre as relações estabelecidas com as novas gerações, os livros infantis sinalizam aspectos da configuração de poder aí estabelecida entre elas e as mais velhas. Permitem a análise sobre elementos de uma sensibilidade historicamente desenvolvida e que repercute nas formas de distanciamento entre ambas. Ao mesmo tempo, a produção dos objetos de leitura para os pequenos 
leitores também traz, com ela, a partir da perspectiva apresentada por Elias, possibilidades para abordagens que versem sobre as fronteiras culturais que sua idealização, circulação e consumo convergem com a difusão do projeto civilizador, pois, como o historiador Roger Chartier (2004, p.17) sintetizou,

[...] toda divulgação, outorgada ou conquistada, produz ao mesmo tempo

a procura de uma nova distinção. É o que ocorre na trajetória da civilidade (entendida ao mesmo tempo como uma noção normativa e como o conjunto de comportamentos que ela prescreve), já que sua difusão na sociedade inteira, por apropriação ou imposição, a desqualifica junto àqueles cuja identidade própria ela caracteriza - o que os leva a valorizar outros conceitos e outras maneiras.

\section{Sobrevoando uma possibilidade: o estudo do livro infantil e sua inscrição no processo de modernização brasileiro. 0 que perguntar, com Norbert Elias?}

Para uma história do livro infantil no Brasil, seguindo as premissas apresentadas pela teoria dos processos civilizadores, convém inicialmente pensá-la a partir dos horizontes estabelecidos pelas trocas culturais com sua metrópole europeia.

Sua genealogia remeterá diretamente ao conhecimento de obras como a do best-seller francês do século XVIII escrito pela Madame de Ségur ${ }^{\mathbf{1 0}}$ que aqui chegou por meio de uma tradução portuguesa de 1861. 0 título do livro oferece as pistas não só de um conteúdo, mas também de uma sociedade cujos grupos dominantes apostavam na correção de conduta das novas gerações como estratégia de distinção e participação na vida social: Tesouro de Meninas. Ou Diálogos entre uma sábia aia e suas discípulas - nos quais, falando cada uma segundo seu gênio, temperamento e inclinações, procura-se corrigir seus defeitos desde a mais tenra idade; seguido intercaladamente de um compêndio da história sagrada, da fábula, da geografia universal, e de alguns contos morais, para entretê-las agradavelmente.

É justamente no fim do século XIX que a produção nacional no gênero é incentivada de modo articulado às aspirações burguesas de famílias, intelectuais e artistas. 0 papel que os livros para as crianças assumem nesse período, no de-

10. No Brasil, a obra teve uma edição comemorativa em 2008 (LEPRINCE DE BEAUMONT, 2008). senvolvimento do sistema literário nacional e, com ele, do seu campo editorial, sobretudo no 
eixo Rio-São Paulo, relacionou-se à forte expansão da urbanização e da escolarização. A forma pela qual livros, modernidade e civilidade entrelaçam-se, nesse momento, é explicada por Leão (1998, p.15), leitora de Norbert Elias:

Nesta configuração social, o livro destinado às crianças, estava investido de uma missão civilizadora, educativa e patriótica capaz de fazer com que seu destinatário incorporasse através de um habitus de leitura uma consciência de pertencimento à nação. 0 livro, para o público infantil, disseminava a forma de sua eficácia simbólica porque funcionava como uma matriz de invenção da ordem social. As crianças também participavam da construção da fantasia de identificação da elite, pois seriam a antecipação da elite desejada do futuro. Daí um fetiche da infância correlato ao fetiche do livro.

A produção editorial brasileira voltada para crianças daquela época tanto apresentaria títulos baseados em contos morais "exemplares" adaptados do folclore europeu ou nacional - caso das famosas Histórias da Carochinha, da Baratinha ou da Avozinha, publicações da Livraria Antonio Quaresma - como faria circular histórias com apelo nacionalista exacerbado - nas quais Olavo Bilac e Coelho Neto foram expoentes. Posteriormente, foi testemunha da difusão de obras que buscariam o tipicamente brasileiro, odioso do estrangeiro e adepto de um autêntico país de "independência ou morte", com Monteiro Lobato.

Entremeado às tentativas da difusão do impresso, o negócio da leitura e das letras infantis foi interferindo decisivamente no desenvolvimento de lugares, de profissões e de produtos e progressivamente definindo um mercado de questões, de agentes, de estratégias e de públicos no Brasil. De modo que a criação e a multiplicação de atores na produção de livros para as crianças brasileiras confirmaram-se como esforços decisivos na consolidação de nossa ordem social burguesa. ${ }^{11}$

Durante todo o século XX, inúmeros debates sobre a direção que deveria determinar a produção no segmento foram definindo a "natureza" do livro infantil em nosso País, explicitando a ininterrupta concorrência de instituições e, outrossim, as próprias clivagens constituintes do espaço social com as ávidas disputas de seus atores pela legitimidade de posições, de dizeres e de valores.

11. A fim de aprofundar a discussão sobre a constituição de um campo de produção do livro para crianças no Brasil, ver nessa perspectiva: Lajolo; Zilberman, 2007, Leão, 2002 e Soares, 2007. 
Por certo, a crença na leitura e no poder dos livros, progressivamente mais difundida, e a própria esperança na infância e na formação dos hábitos das novas gerações, tão comum nestes debates, repercutiram na consolidação e na legitimidade de uma produção que se explicitou nos consistentes índices de regularidade e no destaque que os infantis passaram a assumir na produtividade do setor editorial nacional e na variedade de nomes, marcas, catálogos e propostas de consumo cultural que passaram a se apresentar no mercado na primeira década do nosso século (Tozzi, 2011).

Esse mercado, tão variado quanto legitimado, emerge, assim, hoje, às pesquisas que tematizam a história da infância e da produção cultural a ela destinada, como terreno dos mais férteis questionamentos, cabendo, aqui, espaço para elencar alguns deles em articulação com a teoria dos processos civilizadores de Norbert Elias que aqui foi explorada:

- se o processo civilizador, em que se inscreve a condição humana moderna, encontra em todas as formas institucionais ou informais de educação o seu continnun, o que a história dos livros infantis - que é também a história da escrita e de suas formas de difusão e apropriação - acresce ao conhecimento dos "homens e mulheres da civilização" que passaram a se constituir nos espaços polifônicos da história?

- em que medida o consumo dessa escrita responde à integração a um projeto de modernidade? Ou seja: que limites e tensões nossa condição de "consumidores de modelos de civilidade" traz com ela? Quais possibilidades?

- se o que se oferece à infância é reflexo de uma distância que se estabeleceu, historicamente, entre adultos e as novas gerações no desenvolvimento das sociedades ocidentais, o que na história veio sendo estabelecido como "infantil”? Por que/ Por quem foi assim representado? Como elaborarmos uma história sociológica dessas representações sobre a infância? Como elas estão se renovando? De que forma, particularmente, o comércio dos livros infantis pode, nessa ótica, potencializar a investigação sobre a polifonia dos projetos de consumo cultural, quer dizer, de educação das sensibilidades, voltados às novas gerações? Como, ao mesmo tempo, o estudo da produção cultural destinada à infância pode ampliar os estudos sobre as clivagens sociais ou sobre as necessidades científicas que vão animando o comércio dos "infantis"? 
- como o pensar configuracional de Norbert Elias renova e potencializa as interpretações sobre a produção cultural voltada à infância, sobretudo o comércio dos livros infantis? Em outras palavras, como ele favorece uma abordagem que a discute na sua imersão em uma teia de determinações que responde sobre tendências, estilos, preocupações, inovações, valores, escolhas, trocas internacionais, etc.?

- como, enfim, renovar os ensinamentos metodológicos e os desdobramentos teóricos de Elias para a instauração dos livros infantis no estudo sociológico da história, das mentalidades e das sensibilidades do passado? ${ }^{12}$

\title{
6. Assim, para não encerrar a "leitura" no presente...
}

\begin{abstract}
Por vezes é útil, para compreender melhor as questões da actualidade, afastarmo-nos delas em pensamento para depois, lentamente, a elas regressarmos. Compreendêmo-las, então, melhor. Pois quem se embrenha apenas nas questões do momento, quem nunca olha para além delas, é praticamente cego. (Elias, 1991, p. 13.).
\end{abstract}

Não tem dez anos no Brasil a aprovação da Lei no 10.753 que, em 2003, instituiu nossa primeira Política Nacional do Livro.

No seu capítulo primeiro, “Da Política Nacional do Livro - Diretrizes Gerais”, no artigo $1^{\circ}$, item II, foi estabelecido o livro como "meio principal e insubstituível da difusão da cultura e transmissão do conhecimento, do fomento à pesquisa social e científica, da conservação do patrimônio nacional, da transformação e aperfeiçoamento social e da melhoria da qualidade de vida." (Brasil, 2003).

Mais recente, de 2007 , são as diretrizes da primeira política pública para o livro e a leitura do País. Elas foram introduzidas com comentários sobre o papel do artefato livro no desenvolvimento social e da cidadania e nas transformações rumo à construção de um projeto de sociedade de organização mais justa, com o acesso de todos às situações letradas, mediante a dimensão de uma Política Pública de Estado. Palavras do então Ministro da Educação, Fernando Haddad:

12. Aqui devendo ser considerados estudos atentos: (i) às representações ou sensibilidades divulgadas pela produção de livros para os pequenos leitores: quer dizer, que explorem livros, catálogos, resenhas, premiações, pareceres, ou seja, todo o universo que se compõe antes da chegada dos livros aos leitores presumidos e; (ii) às escolhas efetuadas pelos leitores infantis ou pelos mediadores de suas leituras, caminho profícuo para alargarmos o conhecimento sobre a história das infâncias, o consumo cultural que a atravessa e as relações que esse estabelece com projetos hegemônicos de sociedade. 
[...] no início do século XXI, quando a sociedade brasileira conta com mais de $97 \%$ das crianças de 7 a 14 anos na escola, o país tem a oportunidade histórica de formar uma geração que teve acesso à educação e formá-la na valorização da leitura, no domínio da escrita, na visão crítica das informações que recebe e no exercício da produção e criação de sentido para suas práticas educacionais. (Brasil, 2007, p. 14.).

Ora, se a gênese da "função-editor" (Chartier, 2001), em nosso País, foi patrocinada por um projeto somente compatível com sociedades modernas, a expansão e a especialização do campo editorial nacional devem ser lidas à luz da emergência de novos e maiores públicos. Chamboredon; Fabiani (1977, p. 66), justamente, mostram que as transformações do mercado de livros da infância se articulam, em última análise, à evolução da escolarização - que modifica a compreensão dos públicos potenciais por parte das editoras.

Sendo as condições pelas quais se produz a necessidade e o incentivo para o consumo da leitura historicamente constituídas, é certo que só “é possível que se leia quando existe um mercado no qual possam ser colocados os discursos concernentes às leituras" (Bourdieu; Chartier, 2001, p. 238). Discursos que alimentam sua difusão. Mas também discursos que traduzem operações de concorrência material e distinção simbólica entre os vários grupos e instâncias que participam deste processo de desenvolvimento capitalista. E o que está em jogo, aqui, é o promissor mercado de consumo dos livros infantis.

Com este artigo, esperamos ter contribuído para apontar que uma abordagem sobre questões da educação das novas gerações - de seus objetos e práticas e dos valores que a perpassam - e, mais especificamente, sobre as necessidades que se vão, historicamente, atravessando seus debates, demanda reconhecer as relações de longa duração que vêm confluindo para sua configuração ideológica que não é nem neutra, nem autônoma - tampouco imutável.

Ao enfatizar que "nossa época é tudo menos um ponto final ou culminância" (Elias, 1993, p. 273), Elias provoca, oportunamente, os estudiosos da infância e da indústria dos artefatos voltados para seu consumo, a reinventarem problemáticas e a acentuarem o refinamento de compreensão sobre as históricas e dinâmicas redes de determinação e de influência que delineiam a condição do “infantil”. Especialmente, a pesquisa sobre o estado da produção dos livros voltada à infância é convidada a 
ganhar com a sociologia da sua ciência, superando fetiches que tendem a fazê-la carecer de teorização e de uma tão necessária análise crítica sobre as concorrências objetivas que, acirradamente, estabelecem-se entre produtores, autores, críticos e consumidores desta mercadoria intelectual - geradora efetiva do que as Ciências Sociais aprenderam a reconhecer como capital econômico e simbólico... 


\section{Referências bibliográficas}

ARIĖS, P. O sentimento da infância. In: ARIĖS, P. História Social da criança e da família. 2. ed. Rio de Janeiro: LTC, 2006. p. 01-105.

BOURDIEU, P.; CHARTIER, R. A leitura: uma prática cultural: debate entre Pierre Bourdieu e Roger Chartier. In: CHARTIER, R. (Dir.). Práticas de leitura. 2. ed. rev. São Paulo: Estação Liberdade, 2001. p. 231-253.

BRASIL. Lei $n^{0}$ 10.753, de 30 de outubro de 2003. Institui a Política Nacional do Livro. Disponível em: 〈http://www.portaleditorial.com.br/lei.htm 〉. Acesso em: 10 maio 2009.

BRASIL. Plano nacional do livro e leitura. Ministério da Educação; Ministério da Cultura. Brasília: MEC, Minc, 2007.

CHAMBOREDON, J.C. ; FABIANI, J.L. Les albums pour enfants, le champ de l'édition et les définitions sociales de l'enfance. In: Actes de la recherche en sciences sociales. Paris, n. 13, p. 60-79, fév. 1977.

CHARTIER, R. Cultura escrita, literatura e história: conversas de Roger Chartier com Carlos Aguirre Anaya, Jesús Anaya Rosique, Daniel Goldin e Antonio Saborit. Porto Alegre: ARTMED, 2001.

CHARTIER, R. Leituras e leitores na França do Antigo Regime. São Paulo: Editora Unesp, 2004.

ELIAS, N. A condição humana. Lisboa, Portugal: DIFEL, 1991.

ELIAS, N. Introdução à Sociologia. 3. ed. reimp. Lisboa, Portugal: Edições 70, 2008.

ELIAS, N. Mudanças na balança nós-eu. In: ELIAS, N. A sociedade dos indivíduos. Rio de Janeiro: Jorge Zahar, 1994a. p. 127-193.

ELIAS, N. O processo civilizador: formação do estado e civilização. Rio de Janeiro: Jorge Zahar Editores, 1993. v. 2. .

ELIAS, N. O processo civilizador: uma história dos costumes. Rio de Janeiro: Jorge Zahar Editores, 1994b. v.1.

ELIAS, N. Norbert Elias por ele mesmo. Rio de Janeiro: Jorge Zahar Editores, 2001.168 p. GÉLIS, J. A individualização da criança. In: CHARTIER, R. (Org.). Do Renascimento ao Século das Luzes. São Paulo: Companhia das Letras, 2009. v. 3. p. 305-320.

GOODY, J. O roubo da "civilização”: Elias e a Europa absolutista. In: GOODY, J. O roubo da História. São Paulo: Contexto, 2009. p. 177-205.

LAJOLO, M.; ZILBERMAN, R. Literatura infantil brasileira: história e histórias. 6.ed. São Paulo: Ática, 2007. 
LEÃO, A. B. Brasil em imaginação: livros, impressos e leituras infantis (1890-1915). São Paulo: USP, 2002. 291 p. Tese (Doutorado) - Programa de Pós-Graduação em Sociologia, Faculdade de Filosofia, Letras e Ciências Humanas da Universidade de São Paulo, São Paulo, 2002.

LEÃO, A. B. Civilização da obediência: por uma sociologia do livro escrito para crianças na república brasileira. In: Revista de Letras. Brasília: Universidade Católica de Brasília, v.1/2, n. 20, p. 12-18, jan./dez. 1998.

LEÃO, A. B. Norbert Elias e a Educação. Belo Horizonte: Autêntica, 2007. 96 p.

LEPRINCE DE BEAUMONT, M. Tesouro de meninas ou Diálogos entre uma sábia aia e suas discípulas. Seleção e prefácio: Ana Maria Machado. Rio de Janeiro: Lexicon, 2008.

SOARES, G. P. Semear horizontes: uma história da formação de leitores na Argentina e no Brasil, 1915-1954. Belo Horizonte, MG: Editora UFMG, 2007.

TOZZI, J. B. Livro infantil no Brasil (2007-2008): marcas em circulação, catálogos de divulgação e infâncias anunciadas. Campinas: Unicamp, 2011. 236 p. Dissertação (Mestrado) - Programa de Pós-Graduação em Educação, Faculdade de Educação da Universidade Estadual de Campinas, Campinas, 2011.

Submetido à publicação em 25 de agosto de 2011.

Versão final aprovada em 19 de abril de 2012. 